\title{
A COMUNICAÇÃO EM ENFERMAGEM E A ARGUMENTAÇÃO RETÓRICA
}

\author{
COMMUNICATION IN NURSING AND RHETORICAL ARGUMENTATION
}

\author{
Adilson Pereira Teodoro \\ Universidade de Franca \\ Maria Flavia Figueiredo \\ Universidade de Franca
}

\begin{abstract}
RESUMO: O objetivo do presente trabalho é observar se as prescrições para a relação dialógica entre cuidador e paciente presentes em manuais didáticos da área de Enfermagem obedecem aos preceitos da teoria Retórica. Para tanto, foram selecionados dois manuais que tratam especificamente da comunicação no ato de cuidar. Essas obras são consideradas referência em comunicação na área de Enfermagem e são amplamente referidas em trabalhos de pós-graduação nessa área. A análise terá como fundamento teórico-metodológico a Retórica, teoria que teve seu desenvolvimento a partir dos estudos de Aristóteles na antiguidade grega, ficando à margem por um longo período e ressurgindo por meio do trabalho de Chaïm Perelman \& Olbrechts-Tyteca, também conhecido como a Nova Retórica. A escolha dessa teoria se deu por ser essa uma ciência que trata diretamente da interação comunicativa entre indivíduos e dos meios que cada um utiliza para fazer crer em suas proposições quando necessário. Os resultados da análise demonstraram que os manuais selecionados como corpus, apesar de não adotarem a mesma terminologia utilizada pela teoria retórica, se valem de preceitos de cunho retórico-argumentativo para construir as prescrições direcionadas aos cuidadores de saúde no momento de sua interação com os pacientes.
\end{abstract}

PALAVRAS-CHAVE: retórica; enfermagem; comunicação; manuais didáticos; relação cuidador-paciente.

ABSTRACT: The aim of this work is to observe if the requirements for the dialogical relationship between caregiver and patient present in textbooks of the Nursing area obey the precepts of the Rhetorical theory. Therefore, we selected two manuals that specifically address communication in care. These books are considered reference in Nursing communication and are widely reported in post-graduate studies in this area. The analysis will be based on the theoretical-methodological background of Rhetoric, a theory that had its development from studies of Aristotle in ancient Greece, was left aside for a long period and rouse again through the work of Chaïm Perelman \& Olbrechts-Tyteca also known as the New Rhetoric. The choice of this theory was due to fact that it is a science that deals directly with the communicative interaction between individuals and the means that they use to make us believe in their proposals when necessary. The analysis results showed that despite the fact that the manuals selected as corpus do not adopt the same terminology used in rhetorical theory, they draw upon precepts of rhetorical and argumentative nature to build prescriptions directed to health care providers at the time of their interaction with patients.

KEYWORDS: rhetoric, nursing; communication; textbooks; patient-caregiver relationship. 


\section{Revista do SELL}

v. $4, n^{\circ} .1$

ISSN: $1983-3873$

\section{INTRODUÇÃO}

A palavra é uma grande dominadora, que com pequeníssimo e sumamente invisível corpo, realiza obras diviníssimas, pois pode fazer cessar o medo e tirar as dores, infundir a alegria e inspirar a piedade.

Platão.

O ambiente hospitalar é diverso, constituído de uma pluralidade de contextos e tem a comunicação como componente essencial em cada um deles. Ela é importante nas ações institucionais no sentido de estabelecer contato com a população que utiliza os serviços de saúde. É ainda igualmente considerada na construção das relações profissionais do hospital ao promover a unidade e o diálogo na diversidade de atores, saberes e fazeres. Não obstante, a comunicação que vem merecendo maior preocupação dentro das unidades hospitalares é aquela relacionada ao momento em que o hospital encontra com seu cliente através da prestação de cuidados que ele demanda. Diferentemente da comunicação organizacional, que tem como característica o planejamento de suas ações e, na maioria das vezes, é implementada por especialistas em comunicação empresarial, a comunicação com os pacientes admitidos no hospital é exercida por profissionais de outras disciplinas durante o ato de cuidar, quase nunca é planejada e não é praticada por alguém com esse fim específico. Esses cuidadores são Enfermeiros de leito, Técnicos em Enfermagem, Fisioterapeutas, Nutricionistas, entre outros. ${ }^{1}$

O avanço tecnológico no campo da saúde vem trazendo inovações também na área da comunicação em espaços hospitalares. São aparelhos intercomunicadores, sistemas de monitoramento de ambientes, softwares modernos para compilação de dados e a inserção dos mesmos em sistemas integrados de prontuário dos pacientes. Dessa forma, os pacientes passam a ser sujeitos amplamente conhecidos pelos seus dados, o que colabora para os diagnósticos e para a própria definição da terapia a ser adotada. Entretanto, nada pode substituir o profissional cuidador no momento de interação com o seu assistido. Momento este que, a despeito de toda tecnologia, constitui-se no encontro capaz de gerar, com confiabilidade, os dados necessários aos sistemas operacionais.

$\mathrm{O}$ ato de cuidar implica o estabelecimento de interação entre sujeitos que participam da realização de ações ou cuidados. O encontro comunicativo entre quem

\footnotetext{
${ }^{1}$ Queremos ressaltar que, neste trabalho, o termo cuidador se refere aos profissionais supracitados e para todos os que atuam diretamente com os pacientes internados cotidianamente e de forma sistemática, cujas práticas dependem da interação comunicativa entre os mesmos.
} 


\section{Revista do SELL}

v. $4, n^{\circ} .1$

ISSN: $1983-3873$

cuida e quem é cuidado se estabelece no cuidar e, embora cercado de objetividade e aparatos técnicos, tem caráter relacional, o que propicia um espaço intersubjetivo entre os actantes. O encontro desses sujeitos é mais que uma ação técnica de troca de informações, é também experiência sensível, que envolve o contato humano através dos sentidos e, sobretudo, por meio da fala que conduz a interação entre eles.

Assim, a comunicação empreendida pelos cuidadores no ato de cuidar é entendida como alicerce do tratamento do paciente, pois a qualidade da comunicação estabelecida no cuidado se reflete nas suas atitudes, padrões de reações e participação, implicando a eficácia de tais cuidados na recuperação da sua saúde ou readaptação a uma nova condição de vida. (PEREIRA \& AZEVEDO, 2005, p. 153)

Essa comunicação é basilar também na gestão hospitalar, pois se temos clientes satisfeitos, certamente teremos melhores índices que impactam positiva e diretamente na construção da imagem, tanto dos indivíduos cuidadores, quanto do próprio sistema de saúde; o qual, além da melhora na aceitação pública, pode contar com a otimização dos custos, com a redução de taxas importantes e com a diminuição do retrabalho causado pelas insatisfações dos clientes.

Nesse alto grau de influência na qualidade dos serviços de saúde, a interação comunicativa entre cuidador e paciente passa a ser um tema relevante e alvo de especulações por parte dos administradores hospitalares, dos planos de saúde, dos governos, das faculdades e das próprias categorias diretamente envolvidas. Com isso, o aparecimento de estudos e eventos que tratam da temática é mais frequente, a preocupação com a formação dos profissionais cuidadores, embora incipiente, já se revela em produções que tratam especificamente da comunicação em contexto hospitalar. São obras que visam discutir aspectos inerentes à comunicação na relação de cuidado, propondo, aos agentes de saúde, comportamentos comunicativos que os possam auxiliar em suas relações com os pacientes (cf. OLIVEIRA, 2000; BRAGA, 2004; MARCOLINO et al., 2004; ORIÁ, 2004).

Esta pesquisa se justifica, pois, pelo fato de aliar dois campos distintos do conhecimento humano, a Enfermagem e a Linguística. É nessa interface que o presente trabalho encontrará espaço para se desenvolver. Obviamente, esta pesquisa não será extensiva a todo tipo de comunicação exercido no universo Hospitalar, mas tão somente à existente nos momentos interativos do relacionamento entre cuidador e paciente.

Dentre as diversas possibilidades de abordagem teórica, este trabalho fará uso da Retórica, teoria que teve seu desenvolvimento a partir dos estudos de Aristóteles na 


\section{Revista do SELL}

v. $4, n^{\circ} .1$

ISSN: $1983-3873$

antiguidade grega, ficando à margem por um longo período e ressurgindo através do trabalho de Chaïm Perelman \& Olbrechts-Tyteca intitulado Tratado de Argumentação, também conhecido como a Nova Retórica. A escolha da Retórica deu-se por ser uma ciência que trata diretamente da interação comunicativa entre indivíduos e dos meios que cada um utiliza para fazer crer em suas proposições quando necessário. Os estudos desses meios, sobretudo após a Nova Retórica, sugerem uma argumentação presente no efetivo uso da linguagem, em que considera os diferentes sujeitos, lugares e contextos sociais. Dessa forma, esses estudos abrem espaço para uma diversidade de possibilidades de aplicação em outras áreas que visam estudar o comportamento comunicativo de indivíduos que visam ver suas teses aceitas.

Assim, definida como a ciência do cuidado, a Enfermagem é uma dentre várias áreas do conhecimento humano que precisam estudar o seu fazer comunicativo, pois que depende da aceitação das suas mensagens pelos seus assistidos. Para tanto, necessita de uma competência comunicativa sui generis, onde a linguagem, na interatividade entre os indivíduos nela envolvidos, deve construir uma relação saudável, de vital importância na obtenção de resultados de qualidade, tanto para o paciente quanto para a instituição. A busca por essa competência específica para o profissional assistente de saúde tem sido trabalho de poucos. Apesar de haver trabalhos que abordam o tema, são raras as obras que se propõem a tratar a temática de forma didática e poucas são as pesquisas que estudam a comunicação como instrumento terapêutico.

Duas disciplinas distintas, porém, próximas. A Retórica, na visão aristotélica, é definida como arte de descobrir meios para persuadir, e a Enfermagem, na visão de Florence Nightingale (1989, p. 9), é definida como uma arte que, para ser executada, "requer uma devoção tão exclusiva, um preparo tão rigoroso, quanto a obra de qualquer pintor ou escultor. É uma das artes; poder-se-ia dizer, a mais bela das artes!". Além da proximidade conceitual entre esses dois campos, eles também guardam similaridade em seus percursos históricos. Ambos constituem práticas tão antigas que é difícil de precisar o seu advento na história da humanidade. A Retórica provavelmente é tão antiga quanto a necessidade de comunicação, necessária aos homens na organização social; a enfermagem, não menos antiga, surgiu quando alguém dentro destas comunidades foi destacado para fazer companhia e cuidar dos doentes. Posteriormente, na antiguidade grega, num cenário de efervescência política e social, com Aristóteles, a Retórica adquire o status de um campo de investigação e suas bases como ciência são fixadas. Algo parecido ocorre com a Enfermagem através do aparecimento, em Roma, por volta de 100 


\section{Revista do SELL \\ v. $4, n^{\circ} .1$ \\ ISSN: $1983-3873$}

a.C., dos primeiros lugares próprios para reunir e cuidar dos soldados feridos em batalha. Esses locais podem ser considerados os antecessores dos hospitais modernos.

Retórica e Enfermagem se firmaram como campos epistemológicos e superaram a visão primitiva de que eram apenas arte; a primeira, a arte de bem falar e a segunda, a arte do bem cuidar. Não deixaram de ser arte, porém, mais do que isso, hoje são ciências que tomam o homem como objeto de análise. Se a Retórica, como define Meyer (2007, p. $44 ; 1993$ p. 26), "é o encontro entre os homens e a linguagem na exposição das suas diferenças e das suas identidades", a Enfermagem é um espaço que propicia encontros comunicativos com fins terapêuticos. Entretanto, a despeito do que as aproxima, inexistem estudos que correlacionem os pressupostos teóricos da comunicação em enfermagem às teorias retóricas. Talvez isso se dê em função do pouco espaço que a comunicação ganha durante a formação acadêmica do profissional cuidador. Afirma Stefanelli (1993) que, "apesar de ser unânime a aceitação da relevância da comunicação no ensino, como também o é na assistência e na pesquisa, não se observa coerência entre esse fato e o ensino real que se processa na maioria das instituições formadoras de enfermagem". Dessa forma, as oportunidades de reflexões teóricas por meio de trabalhos científicos tornam-se escassas, restringindo-se aos poucos trabalhos que se apresentam como manuais didáticos do comportamento interacional dos cuidadores, visando levá-los à consciência dos seus atos comunicativos.

Sendo assim, o objetivo do presente trabalho é observar se, nos manuais selecionados, as prescrições para a relação dialógica entre cuidador e paciente são de cunho retórico, e em que medida essa relação coincide com preceitos da teoria retórica.

Para tanto, buscamos materiais que tratassem especificamente a temática da comunicação dentro do ato de cuidar e, apesar da escassez, encontramos duas obras que desenvolvem o assunto com bastante propriedade e que, por isso, as tomamos como corpus para nossa pesquisa.

\section{APRESENTAÇÃO DO CORPUS}

Nossa escolha pelas obras selecionadas para constituir o corpus deste trabalho deveu-se primeiro ao fato de ambas constituírem abordagens específicas sobre a temática da comunicação nos contextos hospitalares e de forma mais acentuada nas interações dos profissionais cuidadores de pacientes hospitalizados, ampliando, dessa forma, a possibilidade de existência dos aspectos que pretendemos analisar: os retórico- 


\section{Revista do SELL \\ v. $4, n^{\circ} .1$}

ISSN: $1983-3873$

argumentativos. Outra razão que justifica nossa escolha é o fato de estas obras aparecerem como duas das mais indicadas como manuais de referência didática em comunicação na área de Enfermagem e serem amplamente referidas em trabalhos de pós-graduação nessa área.

O primeiro livro foi organizado pelas doutoras em Enfermagem Maguida Costa Stefanelli e Emilia Campos de Carvalho, sob o título $A$ comunicação nos diferentes contextos da enfermagem, $2^{\underline{a}}$ edição, 2012. De acordo com as autoras, o livro convida o aluno a refletir sobre o uso da comunicação na prática assistencial do enfermeiro. $\mathrm{Na}$ obra, distribuída em 11 capítulos, as autoras apresentam, por meio de artigos seus e de outras quatro doutoras em Enfermagem, as teorias da comunicação humana utilizadas em enfermagem, os conceitos teóricos sobre comunicação verbal e não verbal, as estratégias de comunicação terapêutica, assim como as dificuldades para sua implementação, além de sugerirem a aplicação dos conhecimentos da comunicação humana no processo de cuidado do paciente e também com os familiares. A obra mostra, ainda, a necessidade de associar esses conhecimentos com as demais competências do enfermeiro. Por fim, apresenta o ensino das habilidades de comunicação necessárias para a aquisição da competência comunicativa e o processo ensino-aprendizagem da comunicação em enfermagem.

O segundo livro a ser analisado, de autoria da doutora Maria Júlia Paes da Silva, intitula-se Comunicação tem remédio: a comunicação nas relações interpessoais em saúde, 8a edição, 2011. Nas palavras da própria autora, a obra é o resultado de um minucioso trabalho de pesquisa, que apresenta ao leitor a aplicação concreta das técnicas de comunicação interpessoal na área de saúde. Ainda segundo ela, Comunicação tem remédio é mais do que um manual, chama também a atenção para a afetividade no dia a dia do trabalho hospitalar, principalmente no relacionamento entre profissionais $\mathrm{e}$ pacientes. O livro enfatiza que a comunicação não se constitui apenas de palavras verbalizadas e que exerce poder de equilíbrio, tanto no tratamento de pacientes, quanto no relacionamento interprofissional. Na obra, a autora mostra que os profissionais da área de saúde têm como base as relações humanas com a equipe multidisciplinar e com pacientes, tais profissionais devem levar em conta o processo comunicativo em que está inserido para um relacionamento positivo e adequado com todos os envolvidos no contexto hospitalar. O livro define o papel da comunicação como um instrumento de bom relacionamento entre cuidadores, pacientes e instituição e age ainda como disseminador dos valores da enfermagem. 


\section{Revista do SELL}

v. $4, n^{\circ} .1$

ISSN: $1983-3873$

Acreditamos que os dois trabalhos supracitados são bastante adequados ao nosso intento científico, por apresentarem uma gama de prescrições didáticas ao comportamento comunicativo dos futuros profissionais da Enfermagem. O ensino das estratégias de interação comunicativa presente nas obras analisadas é o que nos permitirá a verificação da incidência dos conceitos retóricos para, em seguida, mostrarmos as aproximações e os distanciamentos entre a teoria retórica e essas proposições didáticas voltadas à Enfermagem.

\section{ARCABOUÇO TEÓRICO}

\section{RETÓRICA: SUA EMERGÊNCIA}

De acordo com o dicionário Aurélio (2004), a palavra Retórica provém do grego, rhetoriké (subentende-se téchne) e tem sido, ao longo da história, alvo de interpretações muito diversas. Numa acepção mais abrangente, os estudos da retórica incluem a poética, consistindo na arte oratória e da eloquência para proferir discursos de toda ordem (BARILLI, 1987, p. 11). Cabe-nos, aqui, certa delimitação dentre os sentidos possíveis para identificar o que nos interessa neste trabalho. Numa visada mais restrita, que concebe a retórica segundo a definição aristotélica, para quem a retórica é "a faculdade de ver teoricamente o que, em cada caso, pode ser capaz de gerar a persuasão" (ARISTÓTELES, 1988, p. 75), está o sentido pretendido, isto é, o de técnica de construção de discursos persuasivos (aplicável a qualquer disciplina).

O pressuposto das técnicas retóricas, ao orientar a elaboração do discurso persuasivo, é a liberdade do auditório. A retórica não recorre à violência, já que busca ganhar a adesão intelectual do auditório apenas com o uso da argumentação presente em seu discurso. O objetivo de quem argumenta é obter a adesão daquele a quem se dirige, o qual pode, numa escala variável, prestar atenção ou não, acolher ou repelir sugestões propostas pelos argumentos, ou ainda, manifestar-se ou calar-se.

A retórica teve origem na Grécia antiga, com o advento da Polis, e as novas relações sociais que emergiram desse novo ordenamento. É comumente situada pelos estudiosos no século $V$ antes de Cristo, mais especificamente em Siracusa, após a queda do tirano Trasíbulo e o surgimento de inúmeras causas de restituição de direitos diversos, sobretudo os de propriedades perdidas nas ações arbitrárias do tirano deposto. Período no qual fora elaborado o primeiro tratado de Retórica, escrito em 465 a.C. por Tísias e 


\section{Revista do SELL}

v. $4, n^{\circ} .1$

ISSN: $1983-3873$

Córax, que eram oradores que se prestavam à defesa dos direitos dessas vítimas. (ARISTÓTELES, 1988)

Apesar de ter seu surgimento historicamente ligado ao contexto de Siciliano, somente a partir de outro evento numa cidade grega, que a retórica pode de fato se desenvolver de forma contundente. Foi com o aparecimento do regime democrático ateniense, com o surgimento de uma nova classe de pessoas (os cidadãos, aos quais eram dados amplos direitos de deliberação sobre os mais variados assuntos) que a retórica teve seu advento. Com a possibilidade de dirigir-se a outrem em assembleias, com intuito de convencimento acerca de uma nova posição, nasce a necessidade e a importância de exprimir-se bem e saber argumentar.

Esse ambiente tornou-se propício ao aparecimento de professores capazes de formar os futuros oradores que iriam tomar lugar nas assembleias e proferir discursos em defesa de uma tese qualquer. Surgiram, então, os sofistas, que eram mestres da arte oratória e que também formavam os interessados na carreira política. Eram os especialistas da eloquência, em busca de reconhecimento e fortuna. Tornaram-se itinerantes à procura de alunos dispostos a pagar pelo aprendizado e iniciação na arte retórica, ensinando a eles a maneira de serem bem sucedidos por meio do discurso persuasivo.

Assim, sob a forte influência sofística, formavam-se os retores, cidadãos bem sucedidos capazes de intervir, por meio do discurso, na vida política da comunidade. São os sofistas, portanto, os precursores mais importantes da retórica. Esses mestres na oratória, capazes de alavancar uma carreira no serviço público, acabaram por adquirir uma reputação respeitável e, por essa razão, seus ensinamentos eram disputados.

Porém, não foi sem resistência que os métodos sofistas com sua didática do pragmatismo extremo se tornaram protagonistas nos estudos retóricos, pois, se os sofistas gozavam de boa reputação entre os seus contemporâneos, a mesma coisa não se observava nos tempos de Platão, como podemos ver nesta afirmação do filósofo grego: "a retórica é sofística e não tem nada de positivo [...] Longe de assentar no caráter moral do orador, a sofística podia vender-se a todas as causas e foi apresentada antes de mais (sic) como o discurso dos incompetentes, daqueles que só veem fogo e fazem vento". (SOUSA, 2001, p. 22)

Para Platão (1997), as técnicas sofistas não eram científicas, visto que não estavam baseadas em princípios racionais, não demonstrativos. Não buscavam a verdade das coisas e não visavam a excelência, mas, sim, a bajulação, jogando com os desejos e 


\section{Revista do SELL \\ v. $4, n^{\circ} .1$}

ISSN: $1983-3873$

expectativas dos cidadãos. Eram imitações da techné (na área geral de preocupação com a alma humana, Platão inclui a declaração de normas de comportamento, as quais constituem, para ele, a genuína techné). Portanto, essa investigação empírica, conhecida como sofistica, é considerada por Platão como uma atividade espúria.

$\mathrm{Na}$ esteira da herança platônica é que o termo Retórica tem suas origens ligadas às críticas aos sofistas. Não obstante, os males causados pela rejeição de Platão, a retórica assume um papel relevante como objeto nas reflexões dos teóricos gregos, dentre os quais, além do próprio Platão, se destaca Aristóteles.

Apesar das críticas, a retórica contemporânea não desconsidera o mérito dos sofistas e da sua reflexão centrada no homem. Esse mérito abrange sua formação cultural, a pedagogia, o surgimento das técnicas argumentativas e, sobretudo, o questionamento da tradição da sabedoria dos deuses tornando-a um produto terreno.

Em uma via bastante diferente de Platão, Aristóteles irá, após a morte de seu mestre, ser o responsável por disseminar e situar a retórica na cultura ocidental e influenciar muitos teóricos até os nossos dias.

\section{ARISTÓTELES: A GÊNESE DE UMA CIÊNCIA}

Dentro da tradição platônica surge Aristóteles, nascido em Estagira, no norte da Grécia, em 384 a.C. Já como morador de Atenas, tornou-se aluno da academia platônica e nela permaneceu até a morte de Platão, vinte anos após seu ingresso. Fundou sua própria escola, o Liceu, mas, antes disso, foi tutor de Alexandre - o Grande. Porém, foi em sua escola que começou dar importância ao estudo sistemático das diversas disciplinas das artes e das ciências, entre elas a arte retórica.

Apesar de inicialmente fazer coro com as críticas do seu antigo mestre, defendendo a supremacia das teses platônicas, contrárias às práticas dos sofistas, Aristóteles abandona, aos poucos, esse moralismo em favor da incorporação de posições que constroem sua própria concepção de retórica, fruto da influência de seu mestre Platão e daqueles que se opunha.

Aristóteles foi além dos seus precursores, a quem acusa de ensinar, em seus tratados, técnicas desgastadas, exclusivamente aplicáveis à oratória forense. Considerou, conforme Souza (2001), que tais tratados eram pouco satisfatórios, e não passavam do recurso aos truques legais e às formas exageradas de suscitar a compaixão dos jurados. Buscou compreender, mais do que esses discursos judiciais sofistas rejeitados por Platão, 


\section{Revista do SELL \\ v. $4, n^{\circ} .1$ \\ ISSN: $1983-3873$}

a argumentação como recurso de que dispunha o orador no interior dos discursos. Concentrou, assim, seus estudos naquilo que tinha de persuasivo nos discursos e que levava os oradores a obterem a adesão dos ouvintes.

Os estudos aristótélicos evidenciaram uma retórica mais abrangente, correlacionada inclusive com a dialética, ligada ao conhecimento comum e que não se ocupa de um campo específico de uma determinada ciência. É antes aberta às possibilidades criadas pela ação de qualquer indivíduo possuidor da necessidade de sustentar uma opinião e persuadir, por meio de argumentos, qualquer que seja 0 auditório.

Esses meios ou recursos persuasivos de que se vale o orador na sua empreitada diante do seu auditório, são denominados, na teoria aristotélica, como meios de persuasão e classificados em meios técnicos e não técnicos. Por meios não técnicos, ou ainda, provas “não-artísticas" (ARISTÓTELES, 1988), entende-se aqueles que independem do orador para existirem, como as leis, tratados, testemunhos, documentos, etc. Já os meios de persuasão ditos técnicos, ou provas artísticas (ARISTÓTELES, 1988, p. 97), são os que o próprio orador cria no ato da argumentação, ou seja, se ligam à vontade do orador. "De sorte que é necessário usar as primeiras e inventar as segundas" (ARISTÓTELES, 1988, p. 97).

Nas provas não técnicas, aquelas ligadas à criatividade do autor, Aristóteles reconheceu que eram criadas por instâncias diferentes e as apresentou subdivididas em três grupos conforme o contexto de surgimento. Primeiramente o ethos, "aquela que reside no caráter moral do orador [...]. Persuade pelo caráter quando o discurso é proferido de tal maneira que deixa a impressão de o orador ser digno de fé" (ARISTÓTELES, 1988, p. 98). Onde o caráter do orador é central e gerador de persuasão, pois uma pessoa que parece íntegra conquista mais credibilidade do auditório, e de forma mais rápida, deixando-o predisposto ao convencimento. Entretanto, não se trata do caráter real do orador, mas da mera aparência construída no instante do seu discurso, ou seja, a impressão que o orador dá ao auditório sobre quem ele possa ser. 0 pathos, "persuade-se pela disposição dos ouvintes quando estes são levados a sentir emoção por meio do discurso, pois os juízos que emitimos variam conforme sentimos tristeza ou alegria, amor ou ódio" (ARISTÓTELES, 1988, p. 98).

O que podemos depreender desta noção aristotélica é a importância do aspecto emocional envolvido na persuasão. Os sentimentos que o orador consegue despertar no 


\section{Revista do SELL \\ v. $4, n^{\circ} .1$}

ISSN: $1983-3873$

seu ouvinte são determinantes na decisão de ser a favor ou contra a causa que lhe é apresentada.

Finalmente, "persuadimos, enfim, pelo discurso, quando mostramos a verdade ou o que parece verdade, a partir do que é persuasivo em cada caso particular". (ARISTÓTELES, 1988, p. 99). Nesta dimensão, a persuasão é conseguida através do próprio discurso, quando o que é dito ao auditório parece ser a mais pura expressão da verdade. É, pois, na instância do discurso argumentativo, que as principais técnicas retóricas ganham relevância.

Como dissemos, Aristóteles instituiu as bases dos estudos retóricos, dando a eles status de ciência. Com isso, fez com que a retórica ganhasse o mundo e se tornasse essencial no ocidente por um longo tempo. Suas obras são marcos históricos e, ao mesmo tempo, material moderno (ainda atualizado) de consulta.

Teoricamente, a evolução da retórica ao longo dos séculos representou muito mais um aperfeiçoamento da reflexão aristotélica sobre o tema do que construções verdadeiramente originais. E, com certeza, a vertente teórica contida nos trabalhos de Chaïm Perelman e Olbrechts-Tyteca, como será visto a seguir, se abastece nessa fonte aristotélica.

\section{PERELMAN: O RESGATE DA FONTE ORIGINAL E A PRIMAZIA DA RAZÃO}

Perelman \& Olbrechts-Tyteca chamaram de nova retórica o estudo da argumentação, o que já demonstra a sua pesquisa remonta às raízes gregas, particularmente à teoria retórica aristotélica. Ao abandonar sua formação lógica neopositivista, Perelman \& Olbrechts-Tyteca centraram suas pesquisas nos antigos tratados de retórica, de forma mais detida na Retórica e nos Tópicos de Aristóteles, e encontraram neles a possibilidade de colocar os juízos de valor na esfera do racional. Já na introdução do seu Tratado, Perelman \& Olbrechts-Tyteca esclarecem tanto sua vinculação quanto seu propósito: "A publicação de um tratado consagrado à argumentação e a sua ligação a uma velha tradição, a da retórica e da dialéctica gregas constituem uma ruptura com uma concepção da razão e do raciocínio saídos de Descartes, que marcam com o seu selo a filosofia ocidental" (PERELMAN \& OLBRECHTS-TYTECA, 2005, p. 1 grifo do autor).

A Nova Retórica de Perelman \& Olbrechts-Tyteca traz, em lugar da necessidade do encadeamento das ideias no raciocínio lógico cartesiano, a noção do "plausível”, do 


\section{Revista do SELL}

v. $4, n^{\circ} .1$

ISSN: $1983-3873$

"provável" e do "verossímil". A verosimilhança em oposição à evidência empírica favorece o surgimento da noção de racionalidade atrelada à necessidade de adesão do auditório.

Nesse sentido, a teoria da argumentação perelmaniana revitaliza a dimensão prática e subjetiva que lida com valores, que permeiam nossas escolhas, influenciam nossas opiniões e se refletem em nossas decisões. Embora possa ser baseada em aspectos racionais, essa dimensão humana não se prende necessariamente aos critérios subjacentes da lógica formal. É para Perelman \& Olbrechts-Tyteca (2005) a "lógica do preferível", que atinge todo o tipo de raciocínio, em que forma e conteúdo são inseparáveis e cuja compreensão é indissociável da adesão que conseguem promover num auditório.

Assim concebido o processo argumentativo, assentado em bases discursivas, podemos afirmá-lo como possível a toda atividade comunicativa humana que renuncia ao uso da coerção. Desta forma, Perelman \& Olbrechts-Tyteca (2005) reconhecem como fundamental toda relação entre o orador e o auditório, uma vez que o uso da força não seja possível para o convencimento. O auditório aqui definido por Perelman \& OlbrechtsTyteca (2005, p. 22) como "o conjunto de todos aqueles que o orador quer influenciar mediante o seu discurso", reforça que a necessidade de convencer e persuadir implica necessariamente um maior conhecimento desse auditório, visto que, quanto maior for o conhecimento do auditório por parte do orador, maior será o número de acordos prévios ao seu dispor. Tais acordos nascem dos conhecimentos que o orador possui de antemão sobre as teses que o auditório possa admitir como verdadeiras, e que durante uma argumentação, constroem o espaço dos consensos.

Segundo Perelman \& Olbrechts-Tyteca (2005), é pela análise dos diferentes auditórios que podemos melhor compreender a distinção clássica entre convencimento e persuasão, no âmbito da qual se concebem os meios de convencer como racionais e, portanto, dirigidos ao entendimento, e os meios de persuasão como irracionais, atuando diretamente sobre a vontade. A persuasão seria então a consequência natural de uma ação sobre a vontade (Pathos) e o convencimento, o resultado ou efeito do ato de convencer (logos).

Nessa busca pela adesão do auditório, as técnicas argumentativas se apresentarão sob dois aspectos diferentes, assim classificados:

O aspecto positivo consistirá no estabelecimento de uma solidariedade entre teses que se procuram promover e as teses já admitidas pelo auditório: trata-se de argumentos de ligação. "O aspecto negativo visará 


\section{Revista do SELL}

v. $4, n^{\circ} .1$

ISSN: $1983-3873$

abalar ou romper a solidariedade constatada ou presumida entre as teses admitidas e as que se opõem às teses do orador: tratar-se-á da ruptura das ligações e dos argumentos de dissociação" (PERELMAN \& OLBRECHTS-TYTECA, 1987, p. 246).

Os argumentos de ligação se agrupam em três classes: os argumentos quase lógicos, os argumentos fundados na estrutura do real, e aqueles que fundam a estrutura do real. Argumentos quase-lógicos, como o próprio nome sugere, são aqueles cuja estrutura lógica lembra os argumentos da lógica formal, mas que não possuem o mesmo rigor, ou seja, não têm valor conclusivo, constroem-se à imagem de princípios lógicos. Argumentos baseados na estrutura do real são aqueles que se constroem não a partir do que é real, no sentido ontológico, mas do que o auditório acredita que seja real, isto é, aquilo que ele toma por fatos, verdades ou presunções, cujo fundamento encontra-se na ligação existente entre os diversos elementos da realidade. Uma vez que se admite que os elementos do real estejam associados entre si, em uma dada ligação, é possível fundar sobre tal relação uma argumentação que permita passar de um destes elementos ao outro. Finalmente, os argumentos que fundam a estrutura do real é um tipo de argumentação que opera como que por indução, estabelecendo, assim, generalizações e regularidades, propondo modelos, exemplos, anti-modelos, ilustrações a partir de casos particulares (PERELMAN \& OLBRECHTS-TYTECA, 1983, p. 251-258).

Todavia, os elementos de adesão referentes ao orador (ethos) e ao auditório (pathos) não são trabalhados pelos autores tanto quanto o logos. Em Perelman \& Tyteca encontramos dificuldade de separar os elementos trabalhados no espaço em que a sedução atua. Guiada pela necessidade de encontrar aderência ao discurso e não somente sua coerência interna, a teoria de Meyer (1993) defende que a adesão acontece também de forma afetiva, de modo que se torna difícil ver os argumentos isoladamente.

\section{MICHEL MEYER: O RESGATE dO AFETO (A RETOMADA DO ETHOS E DO PATHOS)}

Michel Meyer, Filósofo belga, nascido em 1950, tornou-se o professor que substituiu Chaïm Perelman \& Olbrechts-Tyteca na Universidade de Bruxelas. Mantém uma estreita relação com o fundador da "Nova Retórica" e, como este, funda suas reflexões na teoria aristotélica. É de Meyer o prefácio do Tratado da Argumentação de Perelman \& Olbrechts-Tyteca, confirmando o vínculo da sua emergência. Posiciona-se 


\section{Revista do SELL}

v. $4, n^{\circ} .1$

ISSN: $1983-3873$

mais como um analista da teoria perelmaniana do que necessariamente apropria-se de seus conceitos.

Nessa perspectiva analítica, Meyer (2007, p. 24) afirma, sobre a Nova Retórica, que, embora seus mentores se concentrem no modelo retórico aristotélico, acabam por modificar tal modelo, pois mesmo ampliando suas bases e o seu alcance, eles centraram seus estudos no aspecto argumentativo da retórica, o logos. Para Meyer, os autores do Tratado abordam as questões ligadas às paixões e às emoções com menos importância, visando uma maior racionalidade argumentativa. Neste sentido, podemos dizer que a noção de ethos e de pathos foi resgatada na perspectiva teórica de Michel Meyer, para se igualar em condições com o logos. Essa harmonia entre as três dimensões foi assim defendida por Meyer (MEYER, 2007, p. 25): "decorre que o ethos, o pathos e o logos devem ser postos em pé de igualdade, se não quisermos cair em uma concepção que exclua as dimensões constitutivas da relação retórica. O orador, o auditório e a linguagem são igualmente essenciais".

O enfoque dado na retórica proposta por Meyer recebe por ele mesmo o título de problematológico. Para ele, a argumentatividade retórica se assenta na existência de uma questão que seja susceptível de receber mais do que uma solução. Daí, a questão que se apresenta é o que permite que a negociação entre orador e auditório aconteça. Segundo Meyer (1993), sem uma questão que se coloca, não há possibilidade de debate, nem de discussão, nem de controvérsias, pois que só existiria o consenso.

\section{UM BALANÇO DO CONSTRUCTO TEÓRICO}

Essa apresentação sucinta da teoria retórica presente em três pilares - Aristóteles, Perelman \& Olbrechts-Tyteca e Meyer - nos permite mostrar a relevância que a retórica teve na Antiguidade e que readquiriu na contemporaneidade. Excluída da ciência e da filosofia, a retórica reencontra sua importância nesses teóricos. Antes tida como contrária à lógica, Perelman\& Olbrechts-Tyteca, à luz do logos, buscaram reaproximá-las na medida em que resgataram a concepção aristotélica e propuseram uma argumentação que associa valores e racionalidade. Meyer, na esteira do resgate perelmaniano da dignidade retórica, numa teoria de equilíbrio entre as dimensões que compõem o convencimento, aponta para uma retórica de aplicação multidisciplinar. Permite-nos também o esforço de aproximar a retórica, com essa abrangência ampliada, ao contexto de ensino em Enfermagem. 


\section{Revista do SELL}

v. $4, n^{\circ} .1$

ISSN: $1983-3873$

\section{ANÁLISE DO CORPUS}

\section{METODOLOGIA DE ANÁLISE}

A análise aqui empreendida será exposta da seguinte maneira:

1) enumeração das análises (1, 2, 3 ...);

2) apresentação dos recortes (excertos) de cada um dos livros que compõem o corpus identificados alfabeticamente - a obra organizada por Maguida Stefanelli e Emília Campos de Carvalho será identificada como LA (livro A) e a obra de autoria de Maria Júlia Paes da Silva, como LB (livro B);

3) agrupamento dos excertos em função de sua semelhança ou ligação conceitual. Após os recortes das obras, será inserido o tópico conceitual que os resume;

4) cotejamento dos excertos selecionados com o a teoria retórica que compõe o arcabouço teórico deste trabalho.

\subsection{Análise 1}

LA - "No intercâmbio de mensagens que se processa, o enfermeiro tem de conhecer o repertório do paciente, sua bagagem cultural e de vida, ou seja, entre outros elementos, seu vocabulário, seu linguajar, sua escolaridade, sua origem e suas expectativas, para que o significado das ideias veiculadas no processo de comunicação possa tornar-se comum". (p. 35)

LB - "Para haver efetiva troca de mensagens, é preciso que as palavras usadas tenham um significado comum e conheçamos o repertório do outro, seu grau de escolaridade, vocabulário, expectativas, valores e crenças." (p. 39)

\subsubsection{Tópico: Linguagem adequada ao auditório}

Ambos os excertos evidenciam a necessidade da adequação da linguagem do cuidador em relação ao seu paciente. As expressões a seguir ilustram tal propósito: "conhecer o repertório do paciente" (LA), "é preciso que as palavras usadas tenham um significado comum" (LB).

A adequação da linguagem ao auditório é tida na retórica como ponto crucial. Vejamos como isso se dá:

Aristóteles (1988) enfatiza que o discurso retórico, por querer influenciar, persuadir, se utiliza sempre da linguagem comum ou adaptada conforme as circunstâncias. Já 


\section{Revista do SELL}

v. $4, n^{\circ} .1$

ISSN: $1983-3873$

Perelman e Olbrechts-Tyteca (2005, p. 17) afirmam que o mínimo indispensável para existência de acordos prévios é uma linguagem comum. Meyer (1993), no que se refere à escolha do vocabulário, afirma que o orador deve se preocupar em se comunicar com uma linguagem acessível ao seu auditório. Abreu (2009, p. 15) observa que, num processo argumentativo, nós somos os únicos responsáveis (como oradores) pela clareza de tudo aquilo que dissermos.

\subsection{Análise 2}

LA - "Pode-se falar que a comunicação é efetiva ou eficiente quando o outro oferece uma resposta ou mudança de forma consciente ao demonstrar compreensão da comunicação ocorrida. Isso ocorre quando se oferecem ao outro os elementos para que ele entenda as vantagens e desvantagens de um procedimento, de tratamento ou do limite colocado ao seu comportamento e ele tem a oportunidade de tomar decisões com base em informações adequadas. Para atingir esse estágio, o enfermeiro vale-se de sua competência interpessoal no uso do conhecimento sobre educação humana e das estratégias que tornam a comunicação terapêutica. Desse modo, mesmo que o paciente decida não fazer o tratamento ou submeter-se ao procedimento proposto, a comunicação é considerada bem-sucedida". (p. 36)

LB - "Somente pela comunicação efetiva é que o profissional poderá ajudar o paciente a conceituar seus problemas, enfrentá-los, visualizar sua participação na experiência e alternativas de solução dos mesmos, além de auxiliá-lo a encontrar novos padrões de comportamento". [...] "Mas (a enfermeira) precisa estar atenta ao uso adequado das técnicas da comunicação interpessoal". (p. 14)

\subsubsection{Tópico I: O consentimento e a participação do paciente (como auditório)}

Os trechos acima citam a efetividade da língua como ponto importante para adesão do paciente aos procedimentos. Em LA, a expressão "mudança de forma consciente" sugere seu consentimento e aceitação do proposto. Em LB, o paciente, auxiliado pela comunicação, pode "visualizar sua participação na experiência e alternativas de solução", o que vale dizer, sua aceitação aos procedimentos.

$\mathrm{Na}$ retórica, a adesão do auditório é a sua aceitação das teses propostas pelo orador, vejamos:

Conforme Aristóteles (1998), para haver adesão do auditório é necessário seu assentimento às teses que são apresentadas. Na mesma esteira, Perelman e OlbrechtsTyteca (2005) falam em apreço pela adesão do auditório por parte do orador. Meyer 


\section{Revista do SELL}

v. $4, n^{\circ} .1$

ISSN: $1983-3873$

(1993), por sua vez, disserta sobre a retórica como encontro entre os homens e a linguagem, numa negociação de distâncias para se afirmarem ou se repelirem.

\subsubsection{Tópico II: A liberdade da adesão}

Nos fragmentos do LA, "uma resposta ou mudança de forma consciente" e "mesmo que o paciente decida não fazer o tratamento" de do LB, "poderá ajudar o paciente a conceituar seus problemas" demonstram que a participação do paciente, quando consciente, é uma decisão dele, quando o profissional, com uso da linguagem adequada o leva ao consentimento, sem coerção.

Esse é um tema bastante caro à retórica, uma vez que ela se torna possível exatamente com o princípio de democracia. Vejamos:

Sobre a liberdade dos cidadãos em uma assembleia, Aristóteles (1988) afirma que devemos oferecer razões válidas e racionais para que aceitem ou rejeitem nossas ideias, lúcida e criticamente. Perelman \& Olbrechts-Tyteca (2005, p. 61) advogam essa necessidade de liberdade na adesão quando afirmam: "o recurso à argumentação supõe o estabelecimento de uma comunidade das mentes que, enquanto dura, exclui o uso da violência". Para Meyer (1993), a adesão conseguida sem liberdade é manipulação, um uso indevido da argumentação.

\subsubsection{Tópico III: a competência técnica do orador}

Tanto os excertos do LA - "competência interpessoal no uso do conhecimento" e "estratégias" - como o trecho do LB - "uso adequado das técnicas" - fazem referência à necessidade de uma competência técnica comunicativa, específica para o cuidador obter o consentimento do paciente.

A retórica, desde seus primórdios, é tida como uma técnica e, dessa forma, é dotada de estratégias. E essa técnica foi e, ainda, é objeto de estudo de várias disciplinas.

Para o próprio Aristóteles a retórica é uma técnica que visa descobrir os meios de persuasão mais adequados ao tratamento de questões diversas. E no uso e associação desses meios que ele consegue ou não sucesso diante do seu auditório. Perelman e Olbrechts-Tyteca (2005) corroboram a noção aristotélica ao afirmar que o objeto da retórica é o estudo das técnicas que permitem provocar adesão dos auditórios. Além disso, o uso das estratégias adequadas eleva a possibilidade de adesão do ouvinte. Para 


\section{Revista do SELL}

v. $4, n^{\circ} .1$

ISSN: $1983-3873$

Meyer (1993), que concebe a retórica como a arte de negociar as distâncias entre os retores, sobre uma questão dada, a argumentação é a técnica para reduzir as diferenças e ampliar as identidades rumo ao consenso.

\subsection{Análise 3}

$\mathrm{LA}^{1}$ - "A pessoa que o enfermeiro é e as condições nas quais ele se encontra no momento em que se comunica com o paciente têm importância vital no processo de comunicação [...], pois tudo o que ele é, diz ou faz, ou seja, seu comportamento comunica alguma coisa e pode afetar a resposta do paciente". (p. 37)

$\mathrm{LA}^{2}$ - "O enfermeiro deve [...] valer-se do máximo de clareza possível ao empregar as palavras, o tom e a inflexão da voz na organização das ideias a serem expressas". (p. 38)

LB - "A mensagem são informações ou emoções que queremos passar, as quais não são necessariamente decodificadas da forma como planejamos. Sempre envolve um querer e uma emoção do outro e aquilo que valorizamos no momento". (p. 26)

\subsubsection{Tópico: Ethos, Pathos e Logos.}

No excerto do $L A^{1}$, os dizeres "A pessoa que o enfermeiro é", "pois tudo o que ele é, diz ou faz" e "pode afetar a resposta do paciente" remetem à ideia da imagem social do enfermeiro, isto é, do que o sujeito enfermeiro representa para o paciente, ou, pelo menos, a imagem que ele precisa passar segundo a autora.

Já no segundo trecho ( $\left(\mathrm{A}^{2}\right)$, a preocupação das autoras é com o modo e a forma do dizer do cuidador, que, por certo, afetaria o diálogo. Essa preocupação fica evidente nos trechos: "ao empregar as palavras" e "na organização das ideias a serem expressas".

No terceiro fragmento (LB), é a recepção da mensagem que merece atenção da autora. Os trechos "um querer e uma emoção" e "e aquilo que valorizamos no momento" referem-se ao resultado da comunicação do enfermeiro.

Para a retórica, as condições do orador (ethos), do auditório (pathos) e do próprio discurso (logos) são dimensões presentes no espaço argumentativo e que podem ser exploradas como recursos de persuasão, tal como veremos nos autores elencados abaixo:

Primeiramente, Aristóteles (1988, p. 98), o criador desses conceitos, em sua Retórica, assevera: "Persuade-se pelo caráter (ethos) quando o discurso é proferido de tal maneira que deixa a impressão de o orador ser digno de fé, pois acreditamos mais e bem 


\section{Revista do SELL}

v. $4, n^{\circ} .1$

ISSN: $1983-3873$

mais depressa em pessoas honestas". Ao falar do pathos, Aristóteles (1988, p. 98) afirma: "persuade-se pela disposição dos ouvintes, quando estes são levados a sentir emoção por meio do discurso", uma vez que os sentimentos podem mudar nossa forma de perceber as mensagens. Finalmente, ainda segundo o filósofo, deixamo-nos persuadir facilmente quando nos parece que aquilo que é dito é a verdade e está demonstrado (logos).

Michel Meyer (2007, p. 49), afirma: "Pathos, logos e ethos encontram-se sem que possamos nunca delimitá-los com precisão. A autojustificação implica argumentos (logos), mas também o ter em conta o outro (pathos) a quem se quer agradar para ser aceito ou a quem se quer manipular (ethos)".

Todo discurso pressupõe a construção de uma imagem daqueles que estão envolvidos no processo interativo. Segundo Amossy (2005, p. 37), para o orador construir tal imagem, não é necessário que fale sobre si, de suas qualidades e defeitos, pois, não se trata da sua imagem real, mas da imagem construída pelo auditório a partir de sua fala.

\subsection{Análise 4}

LA - "O profissional da saúde deve ter a consciência de que a cultura é um papel significativo no modo de ser e de se comunicar de cada pessoa, através de crenças e valores, sendo assim não deve levar em consideração apenas as suas características culturais, mas também as do paciente". (p. 38)

LB - "O enfermeiro precisa estar atento às características do paciente, percebê-las e interpretá-las da forma mais fiel possível, avaliando como elas influenciam o modo de ser do paciente. Ao mesmo tempo, o profissional deve conhecer esta singularidade humana e estar consciente de como ela afeta sua comunicação com o outro". (p. 17)

\subsubsection{Tópico: Conhecimento prévio e adaptação ao auditório}

Os termos "cultura", "modo de ser" e "crenças e valores" (do LA) e "características do paciente" e "modo de ser" (no LB) denunciam a singularidade de cada cliente da enfermagem e mostram como cada uma dessas características influenciam na resposta dada ao cuidador. Por outro lado, as expressões "deve ter consciência" e "levar em consideração" (no LA) e "estar atento", "percebê-las e interpretá-las", "conhecer" e "estar consciente" (no LB) mostram a necessidade, por parte do cuidador, de conhecê-las. 


\section{Revista do SELL}

v. $4, n^{\circ} .1$

ISSN: $1983-3873$

A retórica advoga o conhecimento prévio do auditório como condição da adaptação necessária à adesão. Nesses termos, vejamos o que falam os autores com os quais contamos neste trabalho:

Para Aristóteles (1988), o orador deveria conhecer, além das demandas, inclusive, as "paixões" da assembléia, e falar segundo esses conhecimentos, sob pena de não ser aceito nem compreendido pelo seu auditório. Para Perelman e Olbrechts-Tyteca (2005), o objetivo da argumentação é obter ou aumentar a adesão a uma tese dada. Para eles, é preciso reconhecer que adesão só ocorre se o orador se dispuser a conhecer antecipadamente seu auditório e adequar-se a ele. Nessa mesma linha de raciocínio, na teoria de Meyer (1993), podemos associar a esse tópico sua visão da retórica como sendo a negociação da distância entre os homens, pois que tudo o que é desconhecimento do auditório, segundo ele, remete à ampliação da distância, ou seja, ampliam-se as diferenças e diminuem-se os consensos.

\section{Considerações finais}

As análises aqui apresentadas demonstraram que os manuais selecionados como corpus, apesar de não adotarem a mesma terminologia utilizada pela teoria retórica, se valem de preceitos de cunho retórico-argumentativo para construir as prescrições direcionadas aos cuidadores de saúde no momento de sua interação como os pacientes. Portanto, acreditamos que o objetivo proposto na introdução do trabalho tenha sido satisfatoriamente alcançado.

\section{REFERÊNCIAS}

ABREU, Antônio Suárez. A arte de argumentar: gerenciando razão e emoção. 8. ed. São Paulo: Ateliê Editorial, 2009.

AMOSSY, Ruth (org.). Imagens de si no discurso: a construção do ethos. Tradução Dílson Ferreira da Cruz; Fabiana Komesu; Sírio Possenti. São Paulo: Contexto, 2005.

ARISTÓLELES. Retórica. Trad. Manuel Alexandre Júnior, Paulo Farmhouse Alberto e Abel do Nascimento Pena. Lisboa: Imprensa Nacional / Casa da Moeda, 1988.

ARISTÓTELES. Retórica. Lisboa: Imprensa Nacional / Casa da Moeda, 1998.

ARISTÓTELES. Arte retórica e arte poética. 16. ed. Rio de Janeiro: Ediouro, s/d.

BARILLI, Renato. Retórica. Lisboa: Editorial Presença, 1987.

BRAGA, Eliana Mara. Competência em comunicação: uma ponte entre aprendizado e ensino na Enfermagem. São Paulo: E. M. Braga; 2004. 
FERREIRA, Aurélio Buarque de Holanda. Dicionário Aurélio da língua portuguesa: século XXI. Rio de Janeiro: Nova Fronteira, 2004.

NIGHTTINGALE Florence. Notas sobre a enfermagem: o que é e o que não é. São Paulo: Cortez; 1989.

MARCOLINO, J. S. et al. A importância da comunicação na passagem de plantão e sua interferência no processo de trabalho da equipe de enfermagem. Arq. Apadec. v. 8, sup., p. 777-781, 2004.

MEYER, Michel. Questões de retórica: linguagem, razão e sedução. Lisboa: Edições 70, 1993.

MEYER, Michel. A retórica. São Paulo: Ática, 2007.

OLIVEIRA B. G. R. B. A. construção da identidade profissional da enfermeira: a passagem pelos espelhos. (Tese de Doutorado). Rio de Janeiro: Escola de Enfermagem Anna Nery/UFRJ, 2000.

ORIÁ, M. O. B. et al . A comunicação como instrumento do enfermeiro para o cuidado emocional do cliente hospitalizado. Revista Eletrônica de Enfermagem. [online] 2004. Disponível em: <http://www.fen.ufg.br/revista/revista6_2/comunica.html>. Acesso em: 11 de mar. 2012.

PERELMAN, Chaïm. Argumentação. In: Enciclopédia Einaudi. v.11. Lisboa: Imprensa nacional - Casa da moeda, 1987.

PERELMAN, Chaïm e OLBRECHTS-TYTECA, Lucie. Tratado da argumentação. Tradução de Maria Ermantina Galvão G. PEREIRA. São Paulo: Martins Fontes, 2005.

PLATÃO. Górgias. Tradução de Manuel de Oliveira Pulquério. Lisboa: Edições 70, 1997.

SILVA, Maria Júlia Paes. Comunicação tem remédio: a comunicação nas relações interpessoais em saúde. 8. ed. São Paulo: Loyola, 2011.

STEFANELLI, Maguida Costa; CARVALHO, Emilia Campos de; ARANTES, Evalda Cançado. Comunicação e enfermagem. In: STEFANELLI, Maguida Costa; CARVALHO, Emília Campos de. (Orgs.) A comunicação nos diferentes contextos da enfermagem. 2. ed. Barueri: Manole, 2012.

STEFANELLI, Maguida Costa. Comunicação com paciente: teoria e ensino. 2. ed. São Paulo: Robe, 1993. 